\title{
PREDICTION OF WEANING FAILURE OF MECHANICAL VENTILATION USING CLINICAL PARAMETERS IN PICU
}

\author{
Rabab Mohamed El-Beheidy*: Professor of Pediatrics, Faculty of Medicine - Zagazig University, Egypt. \\ Dalia Abdullatif Abdulrahman*: Assistant Professor of Pediatrics, Faculty of Medicine - Zagazig University, \\ Egypt. \\ Sameh Saber Bayoumi*: Lecturer of Diagnostic Radiology, Faculty of Medicine - Zagazig University, Egypt. \\ Walaa Abdul Hakim Hassan: M.B.B.CH of Pediatrics, Faculty of Medicine -Zagazig University, Egypt.
}

Background:Mechanical ventilation is a life support intervention that is used for a large number of patients in Pediatric intensive care units. The current pediatric literature shows that the science of ventilator weaning and extubation remains undetermined. No optimal weaning method has been described for a more rapid and successful extubation.

Objective:Weaning predictors are used as a decision point in protocols to determine whether a patient may advance to a spontaneous breathing trial. We designed a study to determine the effect of including a weaning predictor (clinical weaning parameters) in a weaning protocol.

\section{Subjects \& Methods:}

- Cross section study was conducted on 53 children who admitted to PICU. All patients should be eligible for weaning from mechanical ventilation. Clinical data and laboratory investigations were obtained on admission. Patients underwent a spontaneous breathing trial (SBT) after reversal of the underlying cause for respiratory failure and when they met all the weaning criteria. Then Rapid shallow breathing index (RSBI) was performed. As RSBI $\leq 8$ breath/min/ml/kg, $\mathrm{PaO}_{2}>60 \mathrm{mmHg}, \mathrm{Pa} \mathrm{CO} 2<50 \mathrm{mmHg}, \mathrm{FiO}_{2}<0.5, \mathrm{PaO}_{2} / \mathrm{FiO}_{2}>200 \mathrm{mg}$, Tidal volume $\left(\mathrm{V}_{\mathrm{T}}\right)>5 \mathrm{ml} / \mathrm{kg}, \mathrm{V}_{\mathrm{e}}>200 \mathrm{ml} / \mathrm{min} / \mathrm{kg}, \mathrm{PEEP}<5 \mathrm{CmH}_{2} \mathrm{O}$ and $\mathrm{RR}<45 \mathrm{breath} / \mathrm{min}$.

- Weaning failure is defined as the inability to sustain spontaneous breathing without any form of ventilator support, for at least $48 \mathrm{~h}$. The results were tabulated and analyzed with SPSS.

Results:RSBI differed significantly between patients who succeeded weaning from mechanical ventilation and those who failed (3.12 \pm 1 vs. $9.5 \pm 1.04$ breath $/ \mathrm{min} / \mathrm{ml} / \mathrm{kg} ; \mathrm{P}<0.001)$. A cutoff value $\geq 3.5 \mathrm{breath} / \mathrm{min} / \mathrm{ml} / \mathrm{kg}$ on were associated with a prediction of failure of weaning from mechanical ventilation with a $100 \%$ sensitivity, $75 \%$ specificity, 0.724 positive predictive value (PPV), 1 negative predictive value (NPV) and $84.91 \%$ accuracy.

Conclusion and key messages:Clinical weaning parameter could be considered a sensitive and specific marker for prediction of weaning failure.

Keywords

Weaning; extubation; mechanical ventilation; pediatric Intensive Care Unit; weaning criteria; spontaneous breathing.

Corresponding: Walaa Abdul Hakim Hassan, M.B.B.CH Zagazig University, Zagazig, Sharkeya,Egypt.01023634496,w.alnagaar@gmail.com.

\section{INTRODUCTION}

$\mathrm{M}$ echanical ventilation is a common life support modality in ICUs more than $40 \%$ of ICU patients require mechanical ventilation support as a part of their process of care ${ }^{[1] .}$

The process of ventilatory support follows a continuum of care, beginning with the patient requiring initial support and ending with the ability to sustain spontaneous breathing [2].

Invasive mechanical ventilation is still associated with risks and complications that extend its duration ${ }^{[3]}$ and this augmentation is associated with increased mortality. Therefore, weaning from ventilaton safely and as early as possible is paramount.

Weaning from mechanical ventilation requires dynamic and collaborative decision making to minimize complications and avoid delays in transition to extubation and effective collaboration requires open, extensive, and coordinated communication as well as shared team goals and will result in improved quality 
of care, patient safety and discharge outcomes [4].

Weaning covers the entire process of liberating the patient from mechanical support and from the endotracheal tube ${ }^{[5]}$.

Predicting extubation outcome and preventing extubation failure is, therefore an important task. Various weaning parameters have been suggested to be useful, e.g., minute ventilation $(\mathrm{VE})$, respiratory rate $(\mathrm{RR})$, tidal volume $\left(\mathrm{V}_{\mathrm{T}}\right)$, rapid shallow breathing index (respiratory rate divided by tidal volume, f/VT), maximum inspiratory pressure (PI max), and trans-diaphragmatic pressure (Pdi). However, the prediction rate of these parameters may not be satisfactory. Evaluating the strength of the respiratory muscles becomes important, since the imbalance between respiratory demand and supply will lead to weaning failure through the development of respiratory muscles fatigue ${ }^{[6]}$.

The aim of this work is to assess the role of clinical parameters of weaning in a weaning protocol.

\section{Subjects \& Methods:}

The study was carried out on 53 children who admitted to PICU units in Zagazig University Hospitals with all patients were mechanically ventilated through a tracheostomy or endotracheal tube.

Written consents were taken from the patients' guardians or their relative to participate in this study according to the rules of ethical committee.

Inclusion criteria:

- All patient at PICU < 18 years subjected to mechanical ventilation.

- Patients eligible for weaning from mechanical ventilation according to the following weaning criteria (Evidence for some reversal of the underlying cause for respiratory failure, Adequate oxygenation" $\mathrm{PaO}_{2} / \mathrm{FIO}_{2}$ ratio $\geq 200, \mathrm{FIO}_{2} \leq 0.40$, $\mathrm{PaO}_{2} \geq 60, \mathrm{PaCO}_{2}$ and PEEP $\leq 5$ $\mathrm{cmH}_{2} \mathrm{O}$.",PH $\geq 7.30$, Respiratory rate $\leq$ $45 \mathrm{bpm}$, Heart rate $\leq 140 \mathrm{bpm}, \mathrm{RSBI} \leq$ 8 breaths $/ \mathrm{min} / \mathrm{ml} / \mathrm{kg}$ body weight, Hemodynamic stability" no or minimal vasopressors or inotropes",
Appropriate level of conscious, No continuous sedation infusion nor neuromuscular blocking agents, Afebrile, Adequate hemoglobin $\geq 8$ $\mathrm{g} / \mathrm{dl}$ and/or no evidence of hemorrhage.

Exclusion criteria:

- Any patient with chronic neuromuscular disorder.

- Any patient with known congenital lung or pleural malformation.

- Any patient with primary US revealed unilateral/bilateral absent diaphragmatic mobility.

- Any patient with post esophageal or thoracic surgeries due to intraoperative diaphragmatic manipulation.

- Major cardiac thoracic or abdominal surgery.

All cases underwent the following:

- In all selected patients the followings were done on admission (Institutional Ethics approval was taken from the patient family, date of admission, demographic data "age and sex", preliminary diagnosis).

- Cause of ventilation ( Type I respiratory failure" due to hypoxia", Type II respiratory failure" due to hypoventilation", Type III respiratory failure" due to combined", Type IV respiratory failure" due to hypoperfusion", Present history).

- Past history of: bronchial asthma , heart failure, renal failure

- Vital signs ( heart rate, respiratory rate, blood pressure, temperature)

- Clinical examination (local examination of the patients were scheduled as follows " Chest examination [Inspiction: movement, intercostals retraction \& Palpation: tactile vocal fremitus \& Percussion: resonance, hyperresonance, dullness \& Ausculatation: breath sounds, adventitious sounds]", Girth: chest and abdominal girth during respiration).

- Investigations:

a. Laboratory investigations (Routine investigation: (CBC, Na, K, Urea, 
Creatinine, SGOT, SGPT, PT, INR,) were done, Specific laboratory investigation according to the disease, Arterial blood gasses were obtained as scheduled).

b. Radiological investigations (X ray chest: On admission and when needed, abnormalities, before SBT; Chest ultrasonography; abdominal ultrasonography).

- SBT can be in the form of a low level of pressure support $(5 \mathrm{~cm} \mathrm{H} 2 \mathrm{O})$ or simply as a T-tube breathing. In this study, SBT was done by low level of pressure support. The initial few minutes of the trial, called the screening phase, were monitored closely as most of the detrimental effects of weaning occurs during this period. Thereafter the patient continued the trial for at least 30 minutes but not more than 120 minutes to assess for eligibility for weaning [9].

- Patients were assessed for tolerability of SBT by: (RR> 45/min or change in Respiratory rate $>50 \%$ above baseline, arterial oxygen saturation < $90 \%$, arterial oxygen tension $<50$ $\mathrm{mmHg}$, increase in arterial carbon dioxide tension > $10 \mathrm{mmHg}, \mathrm{HR}$ increase or decrease of $>20 \%$ according to baseline, Agitation, diaphoresis, Signs of increased work of breathing). If any of these criteria were met, SBT was terminated, and these patients were returned to the previous setting of mechanical ventilation ${ }^{[10]}$.

- Patients will be divided into 2 groups according to SBT outcome: Group A who will pass SBT successfully and Group B who will fail SBT.

\section{STATISTICAL ANALYSIS}

Data analyses were performed using IBM SPSS 18.0 and MedCalc 13. Continuous data are expressed as mean $\pm \mathrm{SD}$ and/or median (range), and the categorical variables were expressed as a numbers and percent.

Continuous data were tested for normality using Shapiro Walk test. For normally distributed data, comparisons between two groups were done using independent t-test while for abnormally distributed data, MannWhitney Test was used. Categorical data were compared using Chi-square test ( $\S$ test).All tests were two sided. P-value $<0.05$ was required to reject the null hypothesis. Validity of the screening test (MBL) was assessed in the terms of sensitivity, specificity, predictive value positive, predictive value negative and accuracy.

\section{RESULTS}

The different weaning parameters of the study groups are summarized and illustrated in Table 1.There is highly statistically significant difference between both groups regarding respiratory rat, $\mathrm{PaO}_{2}, \mathrm{PCO}_{2}$, $\mathrm{PaO}_{2} / \mathrm{FiO}_{2}$ rate, $\mathrm{V}_{\mathrm{T}}$ and $\mathrm{RSBI}$. There are statistically significant differences between both groups regarding haemoglobin, heart rate, SBP and PH while there is statistically non-significant difference between both regarding DBP, temperature, $\mathrm{FiO}_{2}, \mathrm{PEEP}$ and $\mathrm{V}_{\mathrm{E}}$.

Table 2 shown that Comparison between the two studied groups according to demographic and ventilatory data. There are highly statistically significant difference between patients with failed weaning and those with successful weaning regarding age, morbidity, days of mechanical ventilation and time of decision of weaning. There is statistically non-significant difference between both groups regarding gender.

Table 3 shows The best cutoff value of RSBI in prediction of failure of weaning was $\geq 3.5$ (Figure 2) with AUROC 1.00, sensitivity $100 \%$, specificity $75 \%$, PPV $72.4 \%$, NPV $100 \%$, +LR 4, -LR 0, accuracy 84.91 $(\mathrm{p}<0.05)$. 
Table 1: Relation between clinical data of studied cases and fate of weaning.

\begin{tabular}{|c|c|c|c|c|c|}
\hline \multirow[t]{2}{*}{ Weaning parameters } & $\begin{array}{l}\text { Failed weaning } \\
\qquad(\mathbf{n}=\mathbf{2 1})\end{array}$ & $\begin{array}{c}\text { Successful } \\
\text { weaning }(n=32)\end{array}$ & & & \\
\hline & Mean \pm SD & Mean \pm SD & Test & $\mathrm{p}$ & Sig \\
\hline RR(breath/min) & $46.52 \pm 7.04$ & $27.88 \pm 4.55$ & $11.736^{*}$ & $<0.001$ & (HS) \\
\hline HB (g/dl) & $10.81 \pm 1.6$ & $11.66 \pm 1.15$ & $-2.239 *$ & 0.03 & $(\mathrm{~S})$ \\
\hline HR (Beats/minute) & $127.67 \pm 16.17$ & $116.94 \pm 15.61$ & $2.413 *$ & 0.019 & $(\mathrm{~S})$ \\
\hline SBP (mmHg) & $114.52 \pm 10.14$ & $107.31 \pm 9.99$ & $2.556^{*}$ & 0.014 & (S) \\
\hline DBP(mmHg) & $68.81 \pm 13.17$ & $64.72 \pm 12.24$ & $1.155^{*}$ & 0.253 & $(\mathrm{NS})$ \\
\hline Temperature $\left({ }^{\circ} \mathrm{C}\right)$ & $37.43 \pm 0.51$ & $37.41 \pm 0.5$ & $0.158 *$ & 0.875 & $(\mathrm{NS})$ \\
\hline PH & $7.34 \pm 0.032$ & $7.37 \pm 0.049^{\circ}$ & $-2.69^{*}$ & 0.009 & $(\mathrm{~S})$ \\
\hline $\mathrm{PaO}_{2}(\mathrm{mmHg})$ & $72.44 \pm 8.81$ & $81.95 \pm 5.53^{\circ}$ & $-4.41 *$ & $<0.001$ & (HS) \\
\hline $\mathrm{PCO}_{2}(\mathrm{mmHg})$ & $46.45 \pm 3.5$ & $40.46 \pm 3.6^{\circ}$ & $5.99 *$ & $<0.001$ & (HS) \\
\hline $\mathrm{PaO}_{2} / \mathrm{FiO}_{2}$ & $343.81 \pm 46.18$ & $388.30 \pm 28.64^{\bullet}$ & $-4.43^{*}$ & $<0.001$ & (HS) \\
\hline $\mathrm{FiO}_{2}$ & $21.19 \pm 0.873$ & $21.13 \pm 0.707$ & $0.3^{*}$ & 0.765 & (NS) \\
\hline $\mathbf{V}_{\mathrm{T}}(\mathrm{ml} / \mathrm{kg})$ & $4.9 \pm 0.59$ & $9.77 \pm 3.36$ & $-8.02 *$ & $<0.001$ & $(\mathrm{HS})$ \\
\hline PEEP $\left(\mathrm{CmH}_{2} \mathrm{o}\right)$ & $4.05 \pm 0.218$ & $3.94 \pm 0.246$ & $1.665^{*}$ & 0.102 & $(\mathrm{NS})$ \\
\hline$V_{E}(\mathrm{ml} / \mathrm{min} / \mathrm{kg})$ & $230.67 \pm 53.66$ & $280.77 \pm 127.28$ & $-0.855^{\S}$ & 0.393 & $(\mathrm{NS})$ \\
\hline RSBI (breath/min/ml/kg) & $9.5 \pm 1.04$ & $3.12 \pm 1$ & $22.35^{*}$ & $<0.001$ & (HS) \\
\hline
\end{tabular}

*Independent sample $\mathrm{t}$ test

$\S$ Mann whitney test

Sig. significance

- significant at $\mathrm{P} \leq 0.05$

Table 2: Comparison between the two studied groups according to demographic and ventilatory data:

$\begin{array}{ccccc}\begin{array}{c}\text { Failed } \\ \text { weaning }\end{array} & \begin{array}{c}\text { Successful } \\ \text { weaning }\end{array} & \text { Test } & p & \text { Sig. }\end{array}$

\begin{tabular}{|c|c|c|c|c|c|}
\hline $\begin{array}{l}\text { Age in months: } \\
\text { mean } \pm \text { SD } \\
\text { median (range) }\end{array}$ & $\begin{array}{c}16.29 \pm 20.49 \\
8(1-72) \\
\end{array}$ & $\begin{array}{c}57.69 \pm 60.67 \\
30(3-170) \\
\end{array}$ & $-3.442 \bullet$ & 0.001 & (HS) \\
\hline $\begin{array}{l}\text { Gender: } \\
\text { Male } \\
\text { Female }\end{array}$ & $\begin{array}{l}10(47.6 \%) \\
11(52.4 \%)\end{array}$ & $\begin{array}{l}17(53.1 \%) \\
15(46.9 \%)\end{array}$ & $0.154 \S$ & 0.695 & (NS) \\
\hline $\begin{array}{l}\text { Morbidity: } \\
\text { Absent } \\
\text { VAP } \\
\text { Pneumothorax } \\
\text { Stridor }\end{array}$ & $\begin{array}{lc}10 & (47.6 \%) \\
7 & (33.4 \%) \\
2 & (9.5 \%) \\
2 & (9.5 \%) \\
\end{array}$ & $\begin{array}{cl}31 & (96.9 \%) \\
0 & (0 \%) \\
0 & (0 \%) \\
1 & (3.1 \%) \\
\end{array}$ & $18.61 \S$ & $<0.001$ & (HS) \\
\hline $\begin{array}{l}\text { Days of MV: } \\
\text { mean } \pm \text { SD } \\
\text { median (range) } \\
\end{array}$ & $\begin{array}{c}12.81 \pm 6.54 \\
12(3-25) \\
\end{array}$ & $\begin{array}{l}7.44 \pm 4.5 \\
7(2-22) \\
\end{array}$ & $-3.102 \bullet$ & $0.002 *$ & (HS) \\
\hline $\begin{array}{l}\text { Time of decision of weaning: } \\
\text { mean } \pm \text { SD } \\
\text { median (range) }\end{array}$ & $\begin{array}{l}9.9 \pm 4.87 \\
10(2-20)\end{array}$ & $\begin{array}{c}5.66 \pm 3.53 \\
5(1-16)\end{array}$ & $-3.406 \bullet$ & $0.001 *$ & (HS) \\
\hline
\end{tabular}

- Mann whitney test

$\S$ Chi square test

Sig. significance 
Table 3: Performance characteristics of RSBI in prediction of failure of weaning.

\begin{tabular}{cccccccccc}
\hline Cutoff & AUC & Sensitivity & Specificity & PPV & NPV & +LR & -LR & Accuracy & p \\
\hline 3.5 & 1.00 & 100 & 75 & 72.4 & 100 & 4 & 0 & 84.91 & $<0.001^{* *}$
\end{tabular}

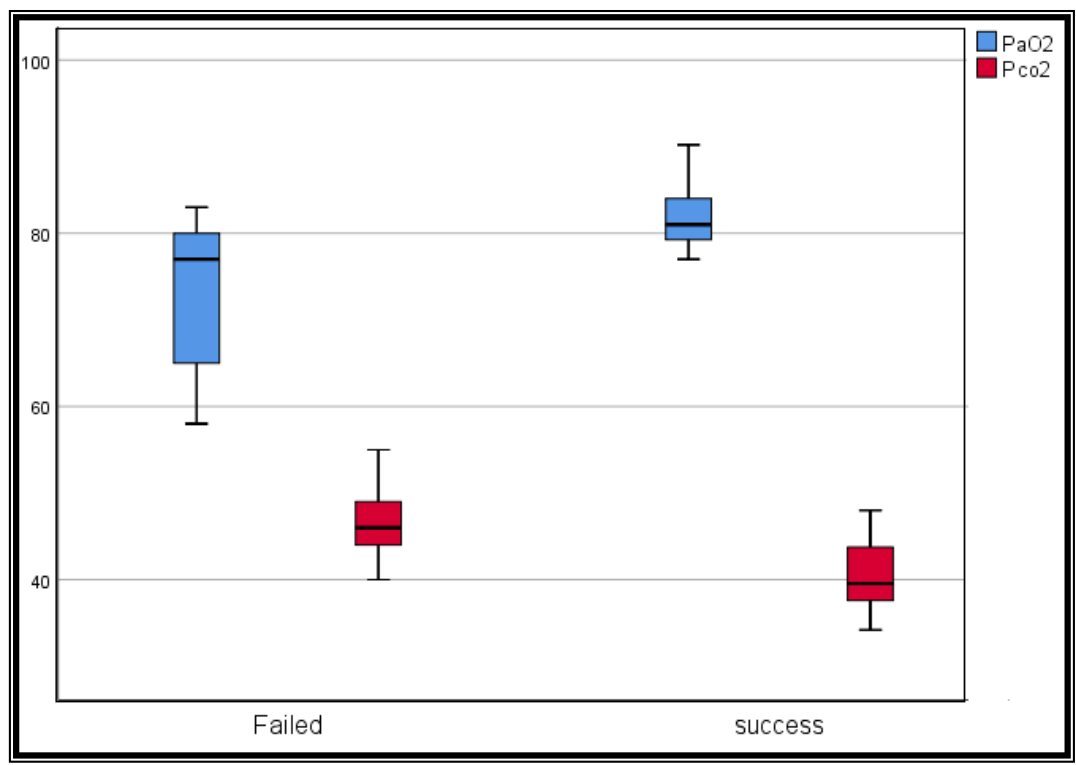

Figure (1): Boxplot showing distribution of studied cases as regarding arterial ABG data and hypoxic indices in relation to fate of weaning

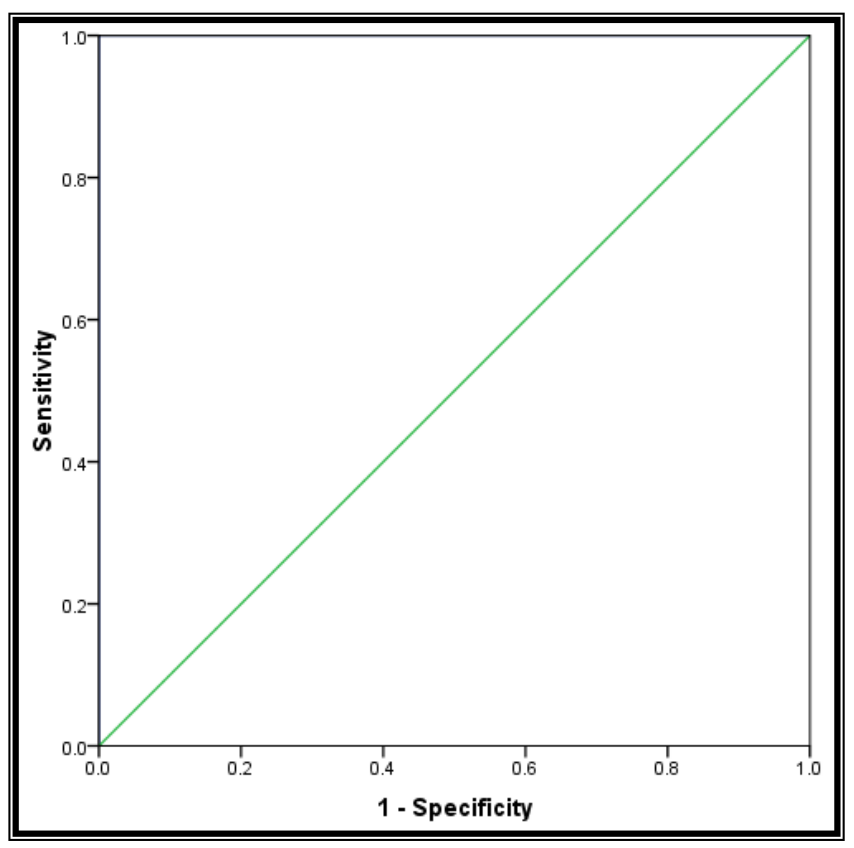

Figure (2): ROC curve to diagnose Failure of weaning using RSBI. 


\section{DISCUSSION}

Weaning from mechanical ventilation requires dynamic and collaborative decision making to minimize complications and avoid delays in the transition to extubation and effective collaboration requires open, extensive, and coordinated communication as well as shared team goals, this will result in improved quality of care, patient safety and discharge outcomes ${ }^{[4] \text {. }}$

Establishing the correct time to extubate mechanically ventilated patients is a crucial issue in the critical care practice [7]. Both premature and delayed extubation prolong the duration of mechanical ventilation and the intensive care unit (ICU) length of stay and increase morbidity and mortality) [8]. Therefore, accurate prediction of postextubation distress and the early diagnosis of the causes responsible for failure of a trial of pressure support ventilation or a trial of totally unsupported respiration ( $\mathrm{T}$ tube) are of paramount importance to improve the outcome of mechanically ventilated patients in the $\mathrm{ICU}^{[8]}$.

Conventional criteria for readiness to wean off MV are relatively easy to use, but their sensitivity and specificity are relatively poor [9]

In the present study the incidence of weaning failure was 21 patients $(39.6 \%)$, and 32 patients $(60.4 \%)$ had successfully completed the spontaneous breathing trial (SBT). $58.5 \%$ of the population was male, compared to $41.5 \%$ female; the main age of the study population was $41.28 \pm 52.67$ Month.

In a study done by Teixeira et al., (2012) studying 533 patients who followed a standard weaning protocol, the incidence of failure from mechanical ventilation was $13.3 \%{ }^{[10]}$. Another study done by Vidotto et al., (2011) on 317 postoperative patients, the incidence of weaning failure was $20 \%$ [11]. This is in controversy to Ferrari et al., (2014) who reported 63\% failure rate, this is explained due to non uniform rule in study population selection with different causes for mechanical ventilation as well as different ventilation periods before starting weaning process which may affect the outcome of the weaning process ${ }^{[12]}$. From the practical point of view the incidence of weaning failure in the 4 studies was relatively high and this gives strength to the theory stating that the present weaning tools are still far away from ideal in expecting success rate of weaning prediction.

Normal vital signs are essential prerequisite before applying weaning from mechanical ventilation. In addition any abnormality in these vital signs could be a vital predictor of weaning failure. the following changes considered to be an early warning for SBT failure; respiratory rate $>45 \mathrm{bpm}$, heart rate change by $>20 \%$ according baseline, systolic blood pressure change by $>20 \%$ according baseline. In the current study there was a significant increase in mean heart rate and systolic blood pressure in failure group as compared to the success one. These mean readings were recorded 30 minutes after applying SBT aiming at early prediction of weaning failure. In agreement with our work, Gnanapandithan et al., (2011). stated that any significant increase in heart rate and systolic blood pressure means failure of SBT [13]

In the present study, normal arterial blood gases $(\mathrm{ABG})$ data were recorded before starting SBT as a part of any standard protocol of weaning. The value of repeating arterial blood gases (ABG) after SBT to decide when to extubate is uncertain. Our study showed that there was highly statistical significant difference between the studied groups as regarding $\mathrm{PaO} 2, \mathrm{PCO} 2$ and $\mathrm{PaO} 2 /$ $\mathrm{FiO} 2$.This agreed with study performed by Keyal et al. (2018) found similar results during studying 108 patients who were planned for extubation, that $\mathrm{ABG}$ can help in identification of patients who can undergo extubation failure ${ }^{[14]}$.

In the current study, the failed SBT group showed a significant increase in respiratory rate with a concomitant significant reduction in tidal volume as compared with the success group. Nemer and Barbas, (2011) found similar results during studying the predictive parameters for weaning from mechanical ventilation ${ }^{[15]}$.

Our results were correlated with many weaning parameters including respiratory 
mechanics with RSBI was one of the most widely used parameter by the other authors for comparison ${ }^{[16]}$. In the present study, the mean values of RSBI was significantly higher $(\mathrm{p}<0.001)$ in failed group $(9.5 \pm 1.04)$ breath $/ \mathrm{min} / \mathrm{ml} / \mathrm{kg}$ than in success group $(3.12 \pm 1) \quad$ breath $/ \mathrm{min} / \mathrm{ml} / \mathrm{kg}$. These results matched with results published by Osman et al., (2017) showed that RSBI higher significant difference during studying the predictive parameters for weaning from mechanical ventilation ${ }^{[17]}$.

Applying the ROC curve to predict the accuracy of the RSBI in weaning failure was $84.91 \%$ with a cut-off point of 3.5 breath $/ \mathrm{min} / \mathrm{ml} / \mathrm{kg}$, meaning that $\mathrm{RSBI} \geq 3.5$ is a good predictor of weaning failure (sensitivity $100 \%$ and specificity $75 \%$ ).

In a study done by Khan $\mathbf{N}$ et al. in 1996 studing 208 children Since then, a cutoff point for the RSBI lower than or equal to 6.5 breath $/ \mathrm{min} / \mathrm{ml} / \mathrm{kg}$ has been accepted to predict extubation success in pediatric patients, but its specificity is low (70\%) (Johnston and Sergio Lucas da Silva, 2012) ${ }^{[8]}$.

Recently, the issue has been revisited in a meta-analysis of 41 RSBI studies by Newth et al., (2009). An editorial that accompanied the meta-analysis suggests that during weaning, the RSBI index can be thought of as a screening test with high sensitivity and low specificity, and therefore should be used early in the course of MV to identify patients who can breathe on their own. Specificity is obtained by applying a confirmatory test such as esophageal pressure trend measurements ${ }^{[18]}$ which are easy to apply in a PICU setting [19]

Most studies with pediatric patients, which showed that the RSBI is not a good extubation predictor, were conducted with patients of different age groups, with different diagnosis and different endotracheal intubation durations. However, when demonstrating that factors such as greater gestational age, postnatal age, intubation time, and birth weight were associated with extubation success or failure ${ }^{[20]}$.

\section{CONCULSION}

Clinical weaning parameter " blood gases, vital signs and the respiratory mechanics can be used to assess the outcome of weaning process.

\section{REFERENCES}

1. Lone, N.I. and Walsh, T.S.: Prolonged mechanical ventilation in critically ill patients: epidemiology, outcomes and modelling the potential cost consequences of establishing a regional weaning unit. Critical Care, 2011;15(2):p.R102.

2. Haas CF and Loik PS.: Ventilator discontinuation protocols. Respiratory care. 2012; 57(10):1649-62.

3. Pierson DJ.: Patient-ventilator interaction. Respiratory care. 2011; 56(2):214-28.

4. Rose L, Blackwood B, Egerod I, Haugdahl HS, Hofhuis J, Isfort M, et al. : Decisional responsibility for mechanical ventilation and weaning: an international survey. Critical Care. 2011;15(6):R295.

5. Boles JM, Bion J, Connors A, Herridge M, Marsh B, Melot C, et al.: Weaning from mechanical ventilation. European Respiratory Journal. 2007;29(5):1033-56.

6. Robriquet $L$, Georges $H$, Leroy $O$, Devos $P$, D'escrivan T, Guery B, et al. : Predictors of extubation failure in patients with chronic obstructive pulmonary disease. Journal of critical care. 2006;21(2):185-90.

7. Mcconville JF, Kress JP.: Weaning patients from the ventilator. The New England journal of medicine. 2013;368(11):1068.

8. Silva S, Aissa DA, Cocquet $P$, Hoarau L, Ruiz J, Ferre F, et al.: Combined thoracic ultrasound assessment during a successful weaning trial predicts postextubation distress. Anesthesiology: The Journal of the American Society of Anesthesiologists. 2017;127(4):66674.

9. Stawicki SP.: Mechanical ventilation: weaning and extubation. International Journal of Academic Medicine.2017; 3(3), 67-71.

10. Teixeira C, Maccari JG, Vieira SR, Oliveira RP, Savi A, Machado AS, et al.: Impact of a mechanical ventilation weaning protocol on the extubation failure rate in difficult-to-wean patients. Jornal Brasileiro de Pneumologia. 2012;38(3):364-71.

11. Vidotto MC, Sogame LC, Gazzotti MR, Prandini M, Jardim JR, et al.: Implications of extubation failure and prolonged mechanical ventilation in the postoperative period following elective intracranial surgery. Brazilian Journal of Medical and Biological Research. 2011; 44(12):1291-8. 
12. Ferrari G, De Filippi G, Elia F, Panero F, Volpicelli G, Aprà F, et al.: Diaphragm ultrasound as a new index of discontinuation from mechanical ventilation. Critical ultrasound journal. 2014;6(1):8-14.

13. Gnanapandithan K, Agarwal R, Aggarwal AN, Gupta D, et al.: Weaning by gradual pressure support (PS) reduction without an initial spontaneous breathing trial (SBT) versus PS-supported SBT: A pilot study. Revista portuguesa de pneumologia. 2011;17(6):24452.

14. Keyal N, Shrestha G, Amatya R, Shrestha P, Acharya S, Marhatta M, et al.: 1117: Influence Of Abg To Guide Extubation In Icu Patients After Spontaneous Breathing Trial. Critical Care Medicine. 2018 Jan 1;46(1):542.

15. Nemer SN and Barbas CS.: Predictive parameters for weaning from mechanical ventilation. Jornal Brasileiro de Pneumologia. 2011;37(5):669-79.

16. Umbrello M, Formenti P, Longhi D, Galimberti, A, Piva, I, Pezzi, A, et al.: Diaphragm ultrasound as indicator of respiratory effort in critically ill patients undergoing assisted mechanical ventilation: a pilot clinical study. Crit Care 2015;19:161.

17. Osman AM and Hashim RM.: Diaphragmatic and lung ultrasound application as new predictive indices for the weaning process in ICU patients. The Egyptian Journal of Radiology and Nuclear Medicine. 2017;48(1):61-6.

18. Newth CJ, Venkataraman S, Willson DF, Meert KL, Harrison R, Dean JM, et al.: Weaning and extubation readiness in pediatric patients. Pediatric critical care medicine: a journal of the Society of Critical Care Medicine and the World Federation of Pediatric Intensive and Critical Care Societies. 2009;10(1):1-11.

19. Argent AC, Newth CJ, Klein M, et al.: The mechanics of breathing in children with acute severe croup. Intensive care medicine. 2008;34(2):324-32.

20. Johnston $C$ and Sergio Lucas da Silva P.: Weaning and extubation in pediatrics. Current Respiratory Medicine Reviews. 2012;8(1):6878. 